\title{
The lactococcal secondary multidrug transporter LmrP confers resistance to lincosamides, macrolides, streptogramins and tetracyclines
}

\author{
Monique Putman, ${ }^{1} \dagger$ Hendrik W. van Veen, ${ }^{1}$ John E. Degener ${ }^{2}$ \\ and Wil N. Konings ${ }^{1}$
}

1 Department of Microbiology, Groningen Biomolecular Sciences and Biotechnology Institute, University of Groningen, Kerklaan 30, 9751 NN Haren, The Netherlands

2 Department of Medical Microbiology, University of Groningen, Hanzeplein 1, 9713 GZ Groningen, The Netherlands

\begin{abstract}
Author for correspondence: Wil N. Konings. Tel: +3150 3632158. Fax: +31503632154. e-mail: w.n.konings@biol.rug.nl
\end{abstract}

The active efflux of toxic compounds by (multi)drug transporters is one of the mechanisms that bacteria have developed to resist cytotoxic drugs. The authors describe the role of the lactococcal secondary multidrug transporter LmrP in the resistance to a broad range of clinically important antibiotics. Cells expressing LmrP display an increased resistance to the lincosamide, streptogramin, tetracycline and 14- and 15-membered macrolide antibiotics. The streptogramin antibiotic quinupristin, present in the fourth-generation antibiotic RP 59500, can inhibit LmrP-mediated Hoechst 33342 transport, but is not transported by LmrP, indicating that quinupristin acts as a modulator of LmrP activity. LmrP-expressing Lactococcus lactis cells in which a protonmotive force is generated accumulate significantly less tetracycline than control cells without LmrP expression. In contrast, LmrP-expressing and control cells accumulate equal amounts of tetracycline in the absence of metabolic energy. These findings demonstrate that the increased antibiotic resistance in LmrP-expressing cells is a result of the active extrusion of antibiotics from the cell.

Keywords: multidrug resistance, multidrug transport, Lactococcus lactis, antibiotic resistance

\section{INTRODUCTION}

The successful introduction of antibiotics in the late 1940s led many to believe that infectious diseases, such as tuberculosis, could be conquered once and for all. The number of multidrug-resistant pathogenic microorganisms, however, demonstrates that microbial antibiotic resistance is a serious threat to public health worldwide (Cohen, 1992; Travis, 1994; Levy, 1998). The ease with which bacteria can exchange genetic material plays an important role in the emergence and spread of multidrug resistance (Davies, 1994; Baquero \& Blázquez, 1997; Saier et al., 1998; Perreten et al., 1997; Anderson, 1999). Therefore, antibiotic resistance

† Present address: Hercules European Research Center, Postbus 252, 3770 AG Barneveld, The Netherlands.

Abbreviation: PMF, proton-motive force. genes from pathogenic as well as from non-pathogenic organisms are of medical importance.

One of the sophisticated biochemical mechanisms that bacteria have developed to evade the lethal effects of toxic drugs is the active efflux of these compounds. In contrast to specific drug-efflux systems, multidrug transporters can extrude a wide variety of structurally unrelated compounds. At present, four classes of multidrug efflux systems have been characterized in bacteria: (i) the ATP-binding cassette superfamily, (ii) the major facilitator superfamily, (iii) the resistance-nodulationdivision family, and (iv) the small multidrug resistance family (Paulsen et al., 1996; van Veen \& Konings, 1998). Many organisms can express several multidrug transporters belonging to different classes.

In the Gram-positive bacterium Lactococcus lactis at least four drug-extrusion activities have been detected (Molenaar et al., 1992; Bolhuis et al., 1994; Glaasker et 
al., 1996). The PMF-driven extrusion of amphiphilic drugs from the inner leaflet of the membrane is mediated by the multidrug transporter LmrP (Bolhuis et al., 1995, 1996). LmrP is a 408 -amino-acid integral membrane protein with 12 putative transmembrane segments, and belongs to the major facilitator superfamily. Extrusion of drugs by LmrP is driven by both the membrane potential and the transmembrane proton gradient, indicating that LmrP mediates an electrogenic proton/ drug antiport reaction (Bolhuis et al., 1996; Putman et al., 1999b).

In this paper we describe the role of the secondary multidrug transporter $\mathrm{LmrP}$ in the resistance to a wide range of clinically important antibiotics that are used to fight infectious diseases. LmrP confers resistance to clindamycin, 14- and 15-membered macrolides, dalfopristin, RP 59500 and tetracycline antibiotics. Hence, LmrP and its endogenous and acquired homologues in pathogenic bacteria are a serious threat to the antibioticbased treatment of patients with infectious diseases.

\section{METHODS}

Antibiotics. Azithromycin (batch 25381-087-02), ceftazidime (batch UCRZ 2500), ciprofloxacin (batch 530949B/1), clarithromycin (batch 33-132VH), clindamycin (batch 44BXC), gentamicin (batch USQ-6-GMF-N-6029) and meropenem (batch $00047 \mathrm{~N}$ ) were generous gifts from Pfizer, Glaxo Wellcome Research and Development, Bayer, IDC Abbott Laboratories, Pharmacia \& Upjohn, Schering-Plough, and Zeneca Pharmaceuticals, respectively. Dalfopristin (batch GRV 1204), quinupristin (batch GRV 1205), RP 59500 (batch CB06274) and spiramycin (batch CA9502600) were gifts from Rhône-Poulenc Rorer. Vancomycin (batch X00336 SI05573) was a gift from Eli Lilly \& Co. Ofloxacin (batch H900) and roxithromycin (batch 5A 3175B) were gifts from Hoechst Marion Roussel. Ampicillin, chloramphenicol and tetracycline were purchased from Boehringer Mannheim. Chlortetracycline, demeclocycline, erythromycin, kanamycin, minocycline, oxytetracycline and $\left[{ }^{3} \mathrm{H}\right]$ tetracycline were obtained from Sigma.

Bacterial strains and growth conditions. The bacterial strains and plasmids used in this study are listed in Table 1. Lactococcus lactis was grown at $30^{\circ} \mathrm{C}$ in M17 medium (Difco) supplemented with $0.5 \%$ glucose $(\mathrm{w} / \mathrm{v})$ plus $5 \mu \mathrm{g}$ chloramphenicol $\mathrm{ml}^{-1}$ when appropriate. Escherichia coli was grown at $37^{\circ} \mathrm{C}$ in Luria Broth containing $50 \mu \mathrm{g}$ ampicillin $\mathrm{ml}^{-1}$ when appropriate.

Preparation of membrane vesicles. L. lactis NZ9000 harbouring the plasmid pHLP5 (Putman et al., 1999a) was grown at $30{ }^{\circ} \mathrm{C}$ to an $\mathrm{OD}_{660}$ of about $0 \cdot 5$. LmrP expression was triggered by the addition of $0 \cdot 1 \%(\mathrm{v} / \mathrm{v})$ of the supernatant of the nisin-A-producing L. lactis strain NZ9700, giving a final concentration of approximately $10 \mathrm{ng}$ nisin $\mathrm{A} \mathrm{ml}^{-1}$. After incubation for $1 \mathrm{~h}$ at $30^{\circ} \mathrm{C}$ the cells were harvested by centrifugation. Inside-out membrane vesicles were prepared using a French pressure cell as described by Putman et al. (1999a). The protein concentration was determined by the Lowry method in the presence of $0.5 \%$ SDS using bovine serum albumin as a standard.

Hoechst 33342 transport. Hoechst 33342 transport mediated by LmrP was studied as described previously (Putman et al., 1999a, b). Inside-out membrane vesicles $\left(0 \cdot 5 \mathrm{mg}\right.$ protein $\left.\mathrm{ml}^{-1}\right)$ were resuspended in $50 \mathrm{mM}$ potassium HEPES, $\mathrm{pH} 7 \cdot 0$, containing $2 \mathrm{mM} \mathrm{MgSO}, 8.5 \mathrm{mM} \mathrm{NaCl}, 0.1 \mathrm{mg}$ creatine kinase $\mathrm{ml}^{-1}$, plus $5 \mathrm{mM}$ phosphocreatine. After $30 \mathrm{~s}$ incubation at $30{ }^{\circ} \mathrm{C}$ Hoechst 33342 was added to $1 \mu \mathrm{M}$ final concentration. LmrP was energized by the generation of a proton-motive force (PMF) by the $\mathrm{F}_{0} \mathrm{~F}_{1} \mathrm{H}^{+}$-ATPase, upon the addition of $0.5 \mathrm{mM} \mathrm{Mg}{ }^{2+}$-ATP. The amount of membraneassociated Hoechst 33342 was measured fluorimetrically (Perkin Elmer LS50B fluorometer), using excitation and emission wavelengths of 355 and $457 \mathrm{~nm}$, respectively, and slit widths of $5 \mathrm{~nm}$ each. The initial rate of Hoechst 33342 transport was determined by linear regression of the fluorescence data obtained in the first $15 \mathrm{~s}$ after $\mathrm{Mg}^{2+}$-ATP addition.

Measurement of the transmembrane $\mathrm{H}^{+}$gradient $(\Delta \mathrm{pH})$ in membrane vesicles. The $\Delta \mathrm{pH}$ (inside acid) in inside-out membrane vesicles was monitored by fluorescence quenching of acridine orange as described previously (Putman et al., 1999a). The transmembrane potential ( $\Delta \psi$, inside positive) in inside-out membrane vesicles was estimated from the increase in $\Delta \mathrm{pH}$ upon dissipation of the $\Delta \psi$ by the addition of the $\mathrm{K}^{+}$ ionophore valinomycin. To study the effect of antibiotics on the PMF, the drugs were added to a final concentration of 1 and 4 times the $\mathrm{IC}_{50}$ for inhibition of LmrP-mediated Hoechst 33342 transport.

Determination of growth rate. For the determination of growth rates in the presence of various antibiotics, overnight E. coli cultures (DH5 $\alpha / \mathrm{pET} 302$ and DH5 $\alpha / \mathrm{pHLP} 1)$ were diluted into fresh medium and grown to mid-exponential phase. The cells were then diluted in fresh medium to an $\mathrm{OD}_{660}$ of 0.025 and $150 \mu \mathrm{l}$ aliquots of the cell suspension were transferred to sterile low-protein-binding 96-well microplates (Greiner), containing $50 \mu \mathrm{l}$ of various concentrations of the antibiotics in fresh medium. For the induction of LmrP expression isopropyl 1-thio- $\beta$-D-galactopyranoside was added to a final concentration of $5 \mu \mathrm{M}$. Aliquots $(50 \mu \mathrm{l})$ of sterile silicone oil were pipetted on top of the sample to prevent evaporation. The cells were grown semi-anaerobically at $30^{\circ} \mathrm{C}$, and the cell density was monitored by measuring the absorbance at $690 \mathrm{~nm}$ every $15 \mathrm{~min}$ for $23 \mathrm{~h}$ in a multiscan photometer (Titretek Multiscan MCC/340 MKII). Growth rates were determined by non-linear least-square fitting of the absorbance data to the Gompertz equation describing bacterial growth (Zwietering et al., 1990). The antibiotic concentrations which inhibited the growth rate by $50 \%\left(\mathrm{IC}_{50}\right)$ were determined.

Tetracycline accumulation in whole cells. L. lactis NZ9000 cells harbouring the control plasmid (pNZ8048) or the LmrPexpression plasmid (pHLP5) were grown at $30{ }^{\circ} \mathrm{C}$ to midexponential phase $\left(\mathrm{OD}_{660} 0 \cdot 5\right)$. Nisin $\mathrm{A}$ was added to a concentration of approximately $10 \mathrm{ng} \mathrm{ml}^{-1}$, to trigger the transcription of the $\operatorname{lmrP}$ gene. Subsequently, the cells were incubated for $1 \mathrm{~h}$ at $30^{\circ} \mathrm{C}$, harvested by centrifugation, washed three times in $50 \mathrm{mM}$ potassium phosphate, $\mathrm{pH} 7 \cdot 0$, containing $0 \cdot 2 \%$ glucose and $1 \mathrm{mM} \mathrm{MgSO}_{4}$, and resuspended in the same buffer to a protein concentration of approximately $0.75 \mathrm{mg} \mathrm{ml}^{-1}$. After a $10 \mathrm{~min}$ preincubation of $100 \mu \mathrm{l}$ aliquots of the cell suspension at $30{ }^{\circ} \mathrm{C},\left[{ }^{3} \mathrm{H}\right]$ tetracycline was added to a final concentration of $5 \mu \mathrm{M}$. At the time points indicated in the legend to Fig. 4, the reaction was stopped by the addition of $2 \mathrm{ml}$ ice-cold $100 \mathrm{mM}$ potassium phosphate, $\mathrm{pH} 7 \cdot 0$, containing $100 \mathrm{mM} \mathrm{LiCl}$. The samples were rapidly filtered through $0 \cdot 45 \mu \mathrm{m}$ pore-size cellulose acetate filters (Schleicher \& Schuell). The filters were washed once with $2 \mathrm{ml}$ ice-cold 
Table 1. Bacterial strains and plasmids

\begin{tabular}{|c|c|c|}
\hline $\begin{array}{l}\text { Strain or } \\
\text { plasmid }\end{array}$ & Relevant properties & Reference or source \\
\hline \multicolumn{3}{|l|}{ Strains } \\
\hline \multicolumn{3}{|l|}{ L. lactis } \\
\hline NZ9000 & MG1363 derivative, $p e p N::$ nisRK & Putman et al. (1999a) \\
\hline NZ9700 & Nisin-producing transconjugant containing TN5276 & Kuipers et al. (1993) \\
\hline \multicolumn{3}{|l|}{ E. coli } \\
\hline $\mathrm{DH} 5 \alpha$ & 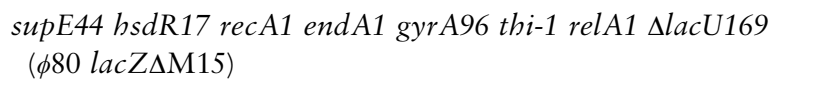 & BRL \\
\hline \multicolumn{3}{|l|}{ Plasmids } \\
\hline pNZ8048 & $\mathrm{Cm}^{\mathrm{R}}, \mathrm{pSH} 71$ replicon, inducible nis $A$ promoter & Putman et al. (1999a) \\
\hline pHLP5 & pNZ8048 carrying His-tagged LmrP of L. lactis & Putman et al. (1999a) \\
\hline pET302 & pTRC99A carrying a His-tag coding region and $t r c$ promoter & van der Does et al. (1998) \\
\hline pHLP1 & pET302 carrying $\operatorname{lm} r P$ on a $1.39 \mathrm{~kb}$ NcoI-XbaI fragment & Bolhuis et al. (1996) \\
\hline
\end{tabular}

$100 \mathrm{mM}$ potassium phosphate, $\mathrm{pH} 7 \cdot 0$, plus $100 \mathrm{mM} \mathrm{LiCl.}$ The radioactivity on the filters was determined by liquid scintillation counting.

\section{RESULTS}

\section{Inhibition of LmrP-mediated drug transport}

To study the specificity of antibiotic binding to LmrP, several classes of clinically important antibiotics were tested for their ability to inhibit the LmrP-mediated transport of Hoechst 33342. The bisbenzimide dye Hoechst 33342 is fluorescent in a lipid environment, but essentially non-fluorescent in aqueous solution. Therefore, the LmrP-mediated transport of Hoechst 33342 from the membrane into the lumen of inside-out membrane vesicles of $L$. lactis can be monitored as a loss of fluorescence in time (Fig. 1a). Antibiotics that are substrates of LmrP compete with Hoechst 33342 for binding to LmrP, and consequently inhibit Hoechst 33342 transport. A typical result, obtained with azithromycin, is shown in Fig. 1(a). From the dose-response curve (Fig. 1b) the concentration giving $50 \%$ inhibition of the initial rate of LmrP-mediated Hoechst 33342 transport $\left(\mathrm{IC}_{50}\right)$ was determined for the various anti-
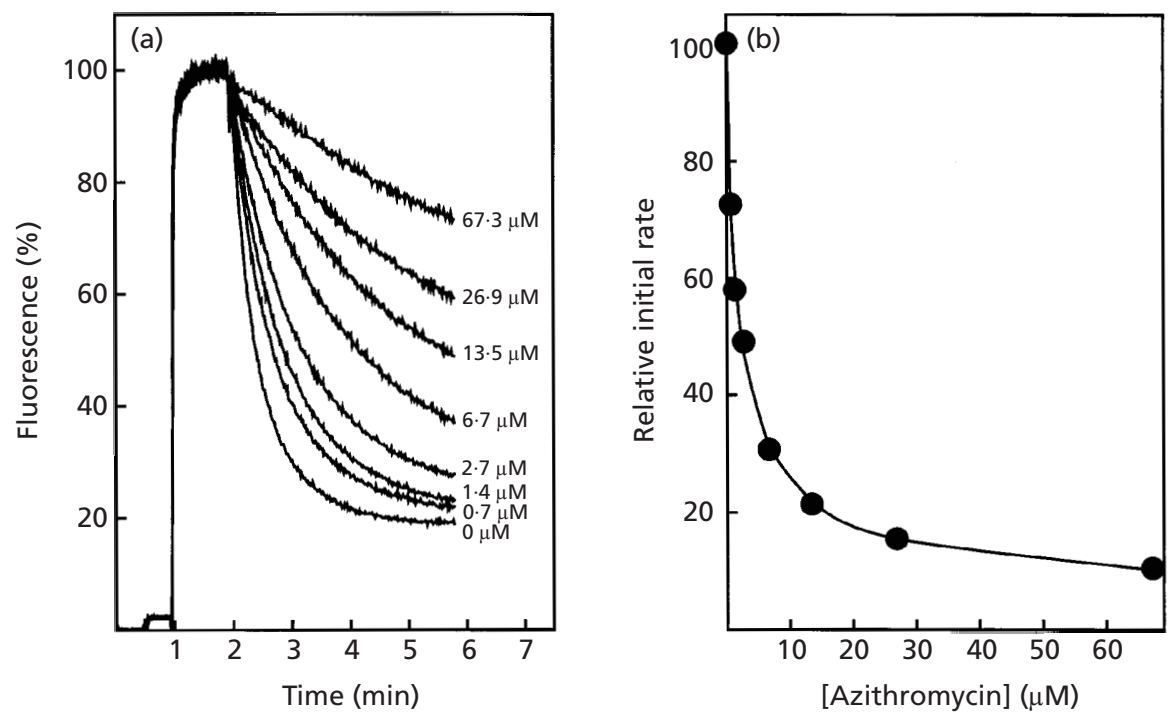

Fig. 1. Inhibition of LmrP-mediated Hoechst 33342 transport by azithromycin. (a) Inside-out membrane vesicles prepared from LmrP-expressing $L$. lactis were diluted to a concentration of $0.5 \mathrm{mg} \mathrm{ml}^{-1}$ in $50 \mathrm{mM}$ potassium HEPES (pH 7.0) containing $2 \mathrm{mM} \mathrm{MgSO}_{4}, 8.5 \mathrm{mM} \mathrm{NaCl}, 0.1 \mathrm{mg}$ creatine kinase $\mathrm{ml}^{-1}$ and $5 \mathrm{mM}$ phosphocreatine. After incubation for $30 \mathrm{~s}$, $1 \mu \mathrm{M}$ Hoechst 33342 was added. Transport was initiated upon the addition of $0.5 \mathrm{mM} \mathrm{Mg}^{2+}$-ATP. The rate of Hoechst 33342 transport was measured in the absence or presence of various concentrations of azithromycin. (b) Determination of the azithromycin concentration giving $50 \%$ inhibition of the initial rate of LmrP-mediated Hoechst 33342 transport $\left(I C_{50}\right)$. The initial rate was determined over the first $15 \mathrm{~s}$ after addition of $0.5 \mathrm{mM} \mathrm{Mg}^{2+}$-ATP. The $\mathrm{IC}_{50}$ was determined by non-linear regression analysis using the general dose-response equation. 
Table 2. Inhibition of LmrP-mediated Hoechst 33342 transport in inside-out membrane vesicles by antibiotics

\begin{tabular}{|llr|}
\hline Class & Antibiotic & $\begin{array}{c}\text { Apparent } \mathrm{IC}_{50} \\
(\boldsymbol{\mu} \mathbf{M})\end{array}$ \\
\hline Lincosamides & Clindamycin & $90 \cdot 1$ \\
Macrolides & Azithromycin & $2 \cdot 0$ \\
& Clarithromycin & $0 \cdot 9$ \\
& Erythromycin & $2 \cdot 6$ \\
& Roxithromycin & $0 \cdot 4$ \\
\multirow{2}{*}{ Streptogramins } & Spiramycin & $60 \cdot 3$ \\
& Dalfopristin & $3 \cdot 5$ \\
& Quinupristin & $11 \cdot 2$ \\
\hline
\end{tabular}

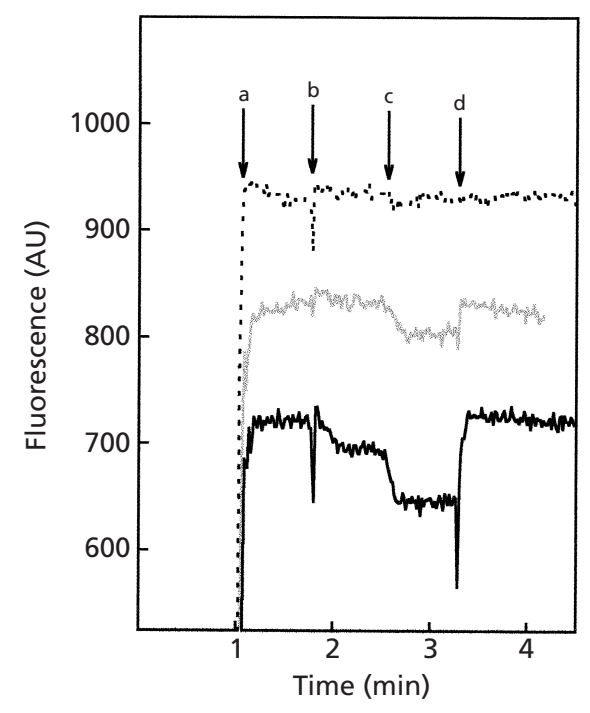

Fig. 2. Effect of antibiotics on the PMF in inside-out membrane vesicles. The $\Delta \mathrm{pH}$-dependent fluorescence of acridine orange in inside-out membrane vesicles of $L$. lactis was measured in the absence (solid black trace) or presence of $90 \mu \mathrm{M}$ clindamycin (solid grey trace) or $60 \mu \mathrm{M}$ spiramycin (dotted black trace). For clarity of presentation, the traces are offset 100 and 200 units from the solid black trace, respectively. Inside-out membrane vesicles were diluted to a concentration of $0.5 \mathrm{mg}$ protein $\mathrm{ml}^{-1}$ in $50 \mathrm{mM}$ potassium HEPES (pH 7.0) containing $2 \mathrm{mM} \mathrm{MgSO}{ }_{4}$, $8.5 \mathrm{mM} \mathrm{NaCl}, 0.1 \mathrm{mg}$ creatine kinase $\mathrm{ml}^{-1}$ and $5 \mathrm{mM}$ phosphocreatine. Acridine orange was added to a final concentration of $1.25 \mu \mathrm{M}$ (a). A PMF (inside acid and positive) was generated by the $\mathrm{F}_{1} \mathrm{~F}_{0} \mathrm{H}^{+}$-ATPase upon the addition of $0.5 \mathrm{mM} \mathrm{Mg} \mathrm{Mg}^{2+}$ ATP (b). Valinomycin (c) and nigericin (d) were added to a final concentration of $1 \mu \mathrm{M}$ each, to interconvert $\Delta \psi$ into $\Delta \mathrm{pH}$, and to dissipate the $\Delta \mathrm{pH}$, respectively.

biotics (Table 2). Since tetracyclines and the quinolones ciprofloxacin and ofloxacin strongly interfered with Hoechst 33342 fluorescence (data not shown) these compounds were not tested. Ampicillin, chloramphenicol, ceftazidime, gentamicin, kanamycin, meropenem, sulfamethoxazol, trimethoprim and vancomycin, added in a 35- to 200-fold excess of Hoechst 33342, did not affect LmrP-mediated Hoechst 33342 transport in inside-out membrane vesicles, indicating

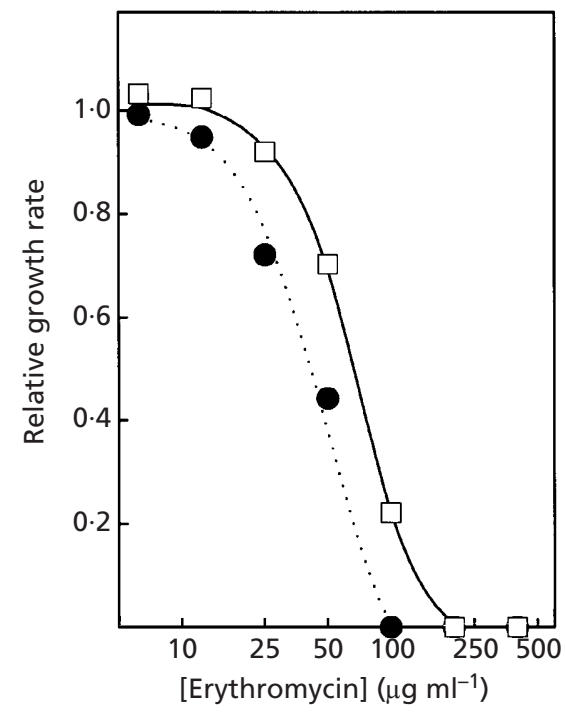

Fig. 3. Effect of erythromycin on the growth rate of $E$. coli DH $5 \alpha$ with and without expression of LmrP. Control cells (DH5 $\alpha / p E T 302,0)$ and LmrP-expressing cells (DH5 $\alpha / p H L P 1, \square)$, were grown semi-anaerobically at $30^{\circ} \mathrm{C}$ on Luria Broth, supplemented with $50 \mu \mathrm{g}$ ampicillin $\mathrm{ml}^{-1}, 5 \mu \mathrm{M}$ IPTG and erythromycin at various concentrations as indicated. The relative growth rate is plotted as a function of the erythromycin concentration.

that these antibiotics do not bind to LmrP. Lincosamide, macrolide and streptogramin antibiotics significantly inhibited LmrP-mediated Hoechst 33342 transport (Table 2).

The antibiotics could inhibit the Hoechst 33342 transport by a direct interaction with LmrP or by interfering with the driving force for LmrP-mediated transport. To analyse the effect of the antibiotics on the PMF, the fluorescent probe acridine orange was used (Fig. 2). Generation of a $\Delta \mathrm{pH}$ (inside acid) causes quenching of acridine orange fluorescence. Upon addition of valinomycin, the fluorescence further decreases, due to the interconversion of $\Delta \psi$ into $\Delta \mathrm{pH}$. The subsequent dissipation of the $\mathrm{pH}$ gradient, by the addition of nigericin, leads to the release of acridine orange from the vesicles, with a concomitant increase in fluorescence (Ramaswamy et al., 1989). This increase is indicative of the magnitude of the PMF that was generated. The acridine orange measurements revealed that azithromycin, clarithromycin, erythromycin, roxithromycin, dalfopristin and quinupristin, at concentrations of up to 4 times their $\mathrm{IC}_{50}$, did not significantly affect the magnitude and composition of the PMF. However, as shown in Fig. 2, clindamycin and spiramycin inhibited the generation of a PMF in the inside-out membrane vesicles at a concentration equal to their respective $\mathrm{IC}_{50}$. These results indicate that clindamycin and spiramycin inhibit LmrP-mediated Hoechst 33342 transport indirectly by interfering with the generation of the driving force for transport, whereas the other macrolide and streptogramin antibiotics interact with LmrP directly. 
Table 3. Antibiotic susceptibilities of $E$. coli $\mathrm{DH} 5 \alpha$ harbouring the LmrP-encoding plasmid pHLP1 or the control plasmid pET302

\begin{tabular}{|c|c|c|c|}
\hline \multirow[t]{2}{*}{ Class } & \multirow[t]{2}{*}{ Antibiotic } & \multicolumn{2}{|c|}{$\mathrm{IC}_{50}\left(\mu \mathrm{g} \mathrm{ml}^{-1}\right)$} \\
\hline & & DH5 $\alpha / \mathrm{pHLP1}$ & DH5 $\alpha /$ pET302 \\
\hline \multirow[t]{2}{*}{ Aminoglycosides } & Gentamicin & $1 \cdot 55 \pm 0 \cdot 21$ & $3 \cdot 00 \pm 0 \cdot 76$ \\
\hline & Kanamycin & $1 \cdot 29 \pm 0 \cdot 18$ & $1 \cdot 41 \pm 0.28$ \\
\hline \multirow[t]{2}{*}{$\beta$-Lactams } & Ceftazidime & $2 \cdot 18 \pm 0 \cdot 87$ & $2 \cdot 78 \pm 1.86$ \\
\hline & Meropenem & $0 \cdot 04 \pm 0 \cdot 02$ & $0 \cdot 04 \pm 0 \cdot 01$ \\
\hline Glycopeptides & Vancomycin & $49 \cdot 6 \pm 2 \cdot 5$ & $51 \cdot 1 \pm 6 \cdot 4$ \\
\hline Lincosamides & Clindamycin & $147 \cdot 9 \pm 21 \cdot 4$ & $65 \cdot 3 \pm 24 \cdot 1$ \\
\hline \multirow[t]{5}{*}{ Macrolides } & Azithromycin & $4 \cdot 00 \pm 1 \cdot 04$ & $2 \cdot 51 \pm 1 \cdot 10$ \\
\hline & Erythromycin & $64 \cdot 1 \pm 7 \cdot 2$ & $32 \cdot 5 \pm 6 \cdot 8$ \\
\hline & Clarithromycin & $55 \cdot 3 \pm 0 \cdot 6$ & $30 \cdot 8 \pm 0 \cdot 6$ \\
\hline & Roxithromycin & $102 \cdot 4 \pm 22 \cdot 0$ & $62 \cdot 4 \pm 23 \cdot 49$ \\
\hline & Spiramycin & $89 \cdot 5 \pm 9 \cdot 6$ & $91 \cdot 7 \pm 8 \cdot 5$ \\
\hline \multirow[t]{2}{*}{ Quinolones } & Ciprofloxacin & $0 \cdot 10 \pm 0 \cdot 11$ & $0 \cdot 18 \pm 0 \cdot 10$ \\
\hline & Ofloxacin & $0 \cdot 04 \pm 0 \cdot 01$ & $0 \cdot 04 \pm 0.01$ \\
\hline \multirow[t]{3}{*}{ Streptogramins } & Dalfopristin & $71 \cdot 9 \pm 22 \cdot 9$ & $41 \cdot 6 \pm 13 \cdot 2$ \\
\hline & Quinupristin & $483 \cdot 1 \pm 14 \cdot 1$ & $426 \cdot 8 \pm 47 \cdot 8$ \\
\hline & RP 59500 & $83 \cdot 7 \pm 3 \cdot 5$ & $58 \cdot 7 \pm 17 \cdot 0$ \\
\hline \multirow[t]{5}{*}{ Tetracyclines } & Chlortetracycline & $0 \cdot 55 \pm 0 \cdot 40$ & $0 \cdot 13 \pm 0.01$ \\
\hline & Demeclocycline & $0 \cdot 30 \pm 0 \cdot 11$ & $0 \cdot 11 \pm 0 \cdot 01$ \\
\hline & Minocycline & $0 \cdot 63 \pm 0 \cdot 16$ & $0 \cdot 41 \pm 0 \cdot 15$ \\
\hline & Oxytetracycline & $0 \cdot 22 \pm 0.08$ & $0 \cdot 12 \pm 0 \cdot 01$ \\
\hline & Tetracycline & $0 \cdot 37 \pm 0 \cdot 25$ & $0 \cdot 12 \pm 0 \cdot 08$ \\
\hline Others & Chloramphenicol & $0 \cdot 81 \pm 0 \cdot 60$ & $0.52 \pm 0.33$ \\
\hline
\end{tabular}

\section{Antibiotic transport by LmrP}

The antibiotic specificity of $\mathrm{LmrP}$ was further studied in cytotoxicity assays. This type of experiment allowed the use of antibiotics which interfered with Hoechst 33342 fluorescence in the previous experiment. In cytotoxicity assays, the antibiotic susceptibilities of cells overexpressing the drug transporter are compared with those of non-LmrP-expressing control cells. Unfortunately, previous work showed that the overexpression of LmrP is detrimental to the cells (Putman et al., 1999a). A positive effect of $\mathrm{LmrP}$ on antibiotic resistance is hard to interpret against a background of growth inhibition by LmrP expression. Therefore the experiments were performed in E. coli cells with a low level of $\mathrm{LmrP}$ expression (DH5 $\alpha / \mathrm{pHLP} 1$, induced with $5 \mu \mathrm{M}$ IPTG), which have a growth rate comparable to that of the control cells (DH5 $\alpha / \mathrm{pET} 302)$.

The growth rates of DH $5 \alpha /$ pET302 and DH $5 \alpha /$ pHLP1 were determined in the presence of a variety of antibiotics. A typical result, obtained with erythromycin, is shown in Fig. 3. The dose-response curve of the LmrPexpressing cells is shifted towards higher erythromycin concentrations, compared to the curve of the control cells, indicating that LmrP increases the resistance to this antibiotic, even at this low level of expression of LmrP. The concentration of the various antibiotics required to inhibit the growth rate by $50 \%\left(\mathrm{IC}_{50}\right)$ is shown in Table 3. Because of the presence of an ampicillin-resistance marker on plasmids pET302 and
pHLP1, ampicillin was not included in the cytotoxicity experiments. Since the sulfonamide antibiotic sulfamethoxazol did not significantly inhibit $E$. coli growth at a concentration of $400 \mu \mathrm{g} \mathrm{ml}^{-1}$ (data not shown), this compound was omitted from further studies.

Comparison of the $\mathrm{IC}_{50}$ values for DH $5 \alpha / \mathrm{pHLP} 1$ and DH $5 \alpha /$ pET302 revealed that the observed differences between the LmrP-expressing and control cells are small. This is due to the very low level of LmrP expression under the conditions used. Only for lincosamides, tetracyclines and a number of macrolide and streptogramin antibiotics was a shift in the dose-response curve (Fig. 3) observed in each single measurement. Although after averaging the measurements some of the data (Table 3) actually overlap in their standard deviation, we consider these antibiotics to be substrates for LmrP.

LmrP consistently increased the resistance to the macrolides azithromycin, clarithromycin, erythromycin and roxithromycin. These macrolide antibiotics contain a 14- or 15 -membered lactone ring that has one or more deoxysugars attached (Woodward, 1957; Ballow \& Amsden, 1992). Interestingly, LmrP did not seem to confer resistance to the 16 -membered macrolide spiramycin. LmrP expression increased the resistance to the streptogramins dalfopristin and RP 59500, but did not affect the resistance to quinupristin. The fourthgeneration antibiotic RP 59500 is a combination of dalfopristin and quinupristin, which demonstrates synergistic and bactericidal activity against Gram-positive 


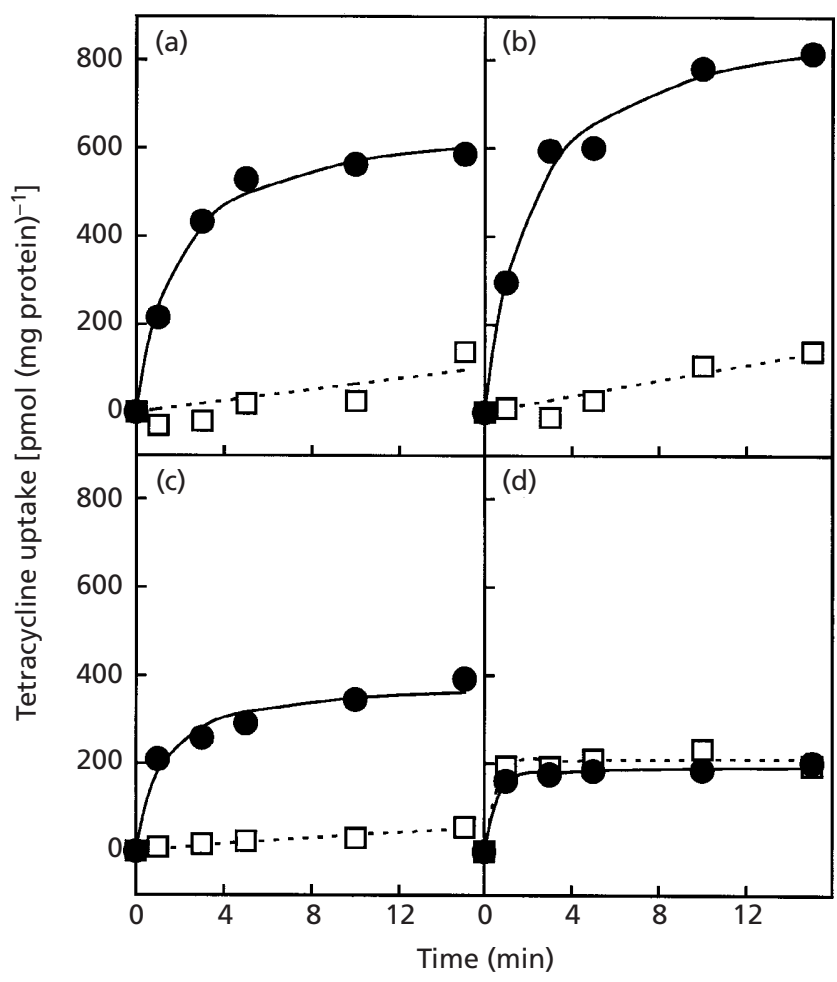

Fig. 4. Effect of ionophores on tetracycline accumulation in $L$. lactis cells. Tetracycline accumulation in $L$. lactis NZ9000/pNZ8048 (control cells, O) and NZ9000/pHLP5 (LmrPexpressing cells, $\square$ ) was measured in cells suspended in $50 \mathrm{mM}$ potassium phosphate, $\mathrm{pH} 7 \cdot 0$, containing $0.2 \%$ glucose and $1 \mathrm{mM} \mathrm{MgSO}{ }_{4}$. The cells $\left(0.75 \mathrm{mg}\right.$ protein $\left.\mathrm{ml}^{-1}\right)$ were incubated for $10 \mathrm{~min}$ at $30^{\circ} \mathrm{C}$, prior to the addition of $5 \mu \mathrm{M}$ $\left[{ }^{3} \mathrm{H}\right]$ tetracycline. The accumulation of tetracycline was determined after 0, 1, 3, 5, 10 and $15 \mathrm{~min}$. The experiments were performed in the absence of ionophores $(\mathrm{a} ; \Delta \mathrm{pH}+\Delta \psi)$ or in the presence of $5 \mu \mathrm{M}$ valinomycin (b; $\Delta \mathrm{pH}$ increased, $\Delta \psi$ dissipated), $5 \mu \mathrm{M}$ nigericin (c; $\Delta \mathrm{pH}$ dissipated, $\Delta \psi$ increased) or both valinomycin and nigericin, each at $5 \mu \mathrm{M}$ (d; both $\Delta \mathrm{pH}$ and $\Delta \psi$ dissipated).

pathogens including methicillin-resistant Staphylococcus aureus (Leclerq \& Courvalin, 1991; Aumercier et al., 1992; Kang \& Ryback, 1995). The LmrP-expressing strain showed higher resistance to all tetracycline antibiotics tested, indicating that substitutions on carbon atoms 5, 6 and 7 do not preclude the interaction between LmrP and the tetracycline antibiotics. LmrP expression did not increase the resistance to aminoglycosides, $\beta$-lactams, glycopeptides, quinolones, and chloramphenicol.

\section{Electrogenic tetracycline transport by LmrP}

To determine whether the observed resistance to tetracycline antibiotics in LmrP-expressing cells is indeed caused by an active extrusion process, the accumulation of tetracycline in LmrP-expressing and control L. lactis cells was measured. In the presence of an energy source the control cells (NZ9000/pNZ8048) accumulated sixfold more tetracycline than the LmrP-expressing
NZ9000/pHLP5 cells (Fig. 4a). Dissipation of the membrane potential by the addition of valinomycin (Fig. 4b) resulted in a slight increase in the amount of tetracycline in the control cells. This is most likely due to an increase in $\Delta \mathrm{pH}$, which is a driving force for the passive influx of tetracycline into the cell (Munske et al., 1984). The accumulation of tetracycline in the LmrPexpressing cells was hardly affected by the addition of valinomycin, indicating that the $\Delta \mathrm{pH}$ is a driving force for LmrP-mediated tetracycline extrusion. Dissipation of the $\Delta \mathrm{pH}$ by the addition of nigericin slightly reduced the high level of tetracycline accumulation in control cells, but did not affect the low level of tetracycline accumulation in LmrP-expressing cells (Fig. 4c). When both components of the PMF were dissipated by the addition of both valinomycin and nigericin (Fig. 4d), equal tetracycline accumulation in both the control and LmrP-expressing cells was observed. These results demonstrate that the increased tetracycline resistance in LmrP-expressing cells is a result of the active extrusion of tetracycline by LmrP. Both the $\Delta \mathrm{pH}$ and $\Delta \psi$ can drive the LmrP-mediated tetracycline efflux, indicative of an electrogenic tetracycline $/ \mathrm{H}^{+}$antiport reaction.

\section{DISCUSSION}

Despite the very low level of expression of LmrP in the cytotoxicity experiments, a consistently increased resistance to four classes of antibiotics was observed. The involvement of LmrP in the resistance to these compounds is supported by the inhibition of LmrP-mediated Hoechst 33342 transport by macrolide and streptogramin antibiotics, and the active transport of tetracycline by LmrP. Altogether, these results indicate that the antibiotic specificity of $\mathrm{LmrP}$ includes lincosamides, 14- and 15-membered macrolides, streptogramins and the tetracycline class of antibiotics. Unlike other secondary multidrug transporters, such as $\mathrm{Acr} A \mathrm{~B}, \mathrm{Bmr}$, MdfA, MexAB, NorA, NorM and Tap, LmrP did not confer resistance to aminoglycosides, $\beta$-lactam antibiotics, quinolones or chloramphenicol (Yoshida et al., 1990; Neyfakh, 1992; Li et al., 1995; Edgar \& Bibi, 1997; Aínsa et al., 1998; Morita et al., 1998; Nikaido et al., 1998).

Although macrolides, lincosamides and streptogramins differ structurally, these antibiotics are often grouped together (MLS antibiotics) because of their similar mechanism of action, which involves the inhibition of protein synthesis through the binding to the 50 S subunit of the bacterial ribosome (Contreras \& Vásquez, 1977). Although the most widespread mechanism of resistance to MLS-type antibiotics is target-site alteration (Weisblum, 1995), this work and other studies (Leclerq \& Courvalin, 1991; Clancy et al., 1996) demonstrate that the resistance to MLS-type antibiotics can also result from enhanced antibiotic efflux. LmrP confers resistance only to the 14 - and 15 -membered macrolides. The macrolide specificity of LmrP resembles that of the multidrug transporter MefA from Streptococcus pyogenes, which confers resistance to 14- and 15- but not to 16-membered macrolide antibiotics (Clancy et al., 
1996). LmrP expression increased the resistance to dalfopristin and RP 59500, but not to quinupristin, suggesting that quinupristin is not transported by LmrP. However, the observed inhibition of LmrP-mediated Hoechst 33342 transport by quinupristin demonstrated that this streptogramin can bind to LmrP. The ability of quinupristin to modulate the activity of multidrug efflux systems may be one of the mechanisms responsible for the synergistic activity of the combination of dalfopristin and quinupristin in antibiotic-based therapy.

Cells expressing LmrP showed an increased resistance to the tetracycline antibiotics. Studies with radio-labelled tetracycline demonstrated that $\mathrm{LmrP}$-expressing cells accumulate significantly less tetracycline than control cells, indicating that the increased tetracycline resistance is due to the active extrusion of tetracycline by $\mathrm{LmrP}$. Dissipation of the $\Delta \mathrm{pH}$ or $\Delta \psi$ only did not increase the accumulation of tetracycline in the LmrP-expressing cells, suggesting that the LmrP-mediated transport of tetracycline is an electrogenic process. This observation is similar to previous observations on the LmrPmediated transport of $\mathrm{TPP}^{+}$(Bolhuis et al., 1996) and Hoechst 33342 (Putman et al., 1999b) and the TetLmediated transport of tetracycline (Guffanti \& Krulwich, 1995). Specific tetracycline transporters, such as TetB of E. coli and TetL of Bacillus subtilis, extrude a complex of tetracycline and a divalent cation in an exchange with one (TetB; Yamaguchi et al., 1990, 1991) or more protons (TetL; Guffanti \& Krulwich, 1995). The role of divalent cations in the LmrP-mediated tetracycline transport will be a subject of further research.

The antibiotic specificity of LmrP indicates that PMFdependent multidrug transporters can affect the efficacy of a number of clinically relevant antibiotics. Although L. lactis is occasionally found as a pathogen in immunocompromised hosts, this bacterium is generally considered to be non-pathogenic and safe to use in starter cultures for cheese production (Gasser, 1994). Given the broad antibiotic specificity of the lactococcal secondary multidrug transporter LmrP and the ATP-binding cassette transporter LmrA (Putman et al., 2000), additional studies are required to determine the probability of transfer of chromosomal resistance genes, such as $\operatorname{lm} r A$ and $\operatorname{lm} r P$, to other bacteria in food or the digestive tract.

\section{ACKNOWLEDGEMENTS}

This work was supported by a grant from the EU program on Structural Biology (BIO-CT-960129).

\section{REFERENCES}

Aínsa, J. A., Blokpoel, M. C. J., Otal, I., Young, D. B., de Smet, K. A. L. \& Martín, C. (1998). Molecular cloning and characterization of Tap, a putative multidrug efflux pump present in Mycobacterium fortuitum and Mycobacterium tuberculosis. J Bacteriol 180, 5836-5843.
Anderson, R. M. (1999). The pandemic of antibiotic resistance. Nat Med 5, 147-149.

Aumercier, M., Bouhallab, S., Capmau, M. L. \& Le Goffic, F. (1992). RP59500: a proposed mechanism for its bactericidal activity. J Antimicrob Chemother 30, 9-14.

Ballow, C. H. \& Amsden, G. W. (1992). Azithromycin: the first azalide antibiotic. Ann Pharmacother 26, 1253-1261.

Baquero, F. \& Blázquez, J. (1997). Evolution of antibiotic resistance. Trends Ecol Evol 12, 482-487.

Bolhuis, H., Molenaar, D., Poelarends, G., van Veen, H. W., Poolman, B., Driessen, A. J. M. \& Konings, W. N. (1994). Proton motive force-driven and ATP-dependent extrusion systems in multidrug resistant Lactococcus lactis. J Bacteriol 176, 6957-6964.

Bolhuis, H., Poelarends, G., van Veen, H. W., Poolman, B., Driessen, A. J. M. \& Konings, W. N. (1995). The lactococcal $l m r P$ gene encodes a proton motive force-dependent drug transporter. J Biol Chem 270, 26092-26098.

Bolhuis, H., van Veen, H. W., Brands, J. R., Putman, M., Poolman, B., Driessen, A. J. M. \& Konings, W. N. (1996). Energetics and mechanism of drug transport mediated by the lactococcal multidrug transporter LmrP. J Biol Chem 271, 24123-24128.

Clancy, J., Petitpas, J., Dib-Hajj, F., Yuan, W., Cronan, M., Kamath, A. V., Bergeron, J. \& Retsema, J. A. (1996). Molecular cloning and functional analysis of a novel macrolide-resistance determinant, mefA, from Streptococcus pyogenes. Mol Microbiol 22, 867-879.

Cohen, M. L. (1992). Epidemiology of drug resistance: implications for a post-antimicrobial era. Science 257, 1050-1054.

Contreras, A. \& Vásquez, D. (1977). Cooperative and antagonistic interactions of peptidyl-tRNA and antibiotics with bacterial ribosomes. Eur J Biochem 74, 539-547.

Davies, J. (1994). Inactivation of antibiotics and the dissemination of resistance genes. Science 264, 375-381.

van der Does, C., Manting, E. H., Kaufmann, A., Lutz, M. \& Driessen, A. J. M. (1998). Interaction between SecA and SecYEG in micellar solution and formation of the membrane-inserted state. Biochemistry 37, 201-210.

Edgar, R. \& Bibi, E. (1997). MdfA, an Escherichia coli multidrug resistance protein with an extraordinarily broad spectrum of drug recognition. J Bacteriol 179, 2274-2280.

Gasser, F. (1994). Safety of lactic acid bacteria and their occurrence in human clinical infections. Bull Inst Pasteur 92, 45-67.

Glaasker, E., Konings, W. N. \& Poolman, B. (1996). The application of $\mathrm{pH}$-sensitive fluorescent dyes in lactic acid bacteria reveals distinct extrusion systems for unmodified and conjugated dyes. Mol Membr Biol 13, 173-181.

Guffanti, A. A. \& Krulwich, T. A. (1995). Tetracycline $/ \mathrm{H}^{+}$antiport and $\mathrm{Na}^{+} / \mathrm{H}^{+}$antiport catalyzed by the Bacillus subtilis TetA(L) transporter expressed in Escherichia coli. J Bacteriol 177, 4557-4561.

Kang, L. \& Rybak, M. J. (1995). Pharmacodynamics of RP59500 alone and in combination with vancomycin against Staphylococcus aureus in an in vitro-infected fibrin cloth model. Antimicrob Agents Chemother 39, 1505-1511.

Kuipers, O. P., Beerthuyzen, M. M., Siezen, R. J. \& de Vos, W. M. (1993). Characterization of the nisin gene cluster nisABTCIPR of Lactococcus lactis: requirement of expression of the nis $A$ and nisI genes for development of immunity. Eur J Biochem 216, 281-291.

Leclerq, R. \& Courvalin, P. (1991). Intrinsic and unusual resistance to macrolide, lincosamide, and streptogramin antibiotics in bacteria. Antimicrob Agents Chemother 35, 1273-1276. 
Levy, S. B. (1998). The challenge of antibiotic resistance. Sci Am 278, 32-39.

Li, X.-Z., Nikaido, H. \& Poole, K. (1995). Role of MexA-MexBOprM in antibiotic efflux in Pseudomonas aeruginosa. Antimicrob Agents Chemother 39, 1948-1953.

Molenaar, D., Bolhuis, H., Abee, T., Poolman, B. \& Konings, W. N. (1992). The efflux of a fluorescent probe is catalyzed by an ATPdriven extrusion system in Lactococcus lactis. J Bacteriol 174, 3118-3124.

Morita, Y., Kodama, K., Shiota, S., Mine, T., Kataoka, A., Mizushima, T. \& Tsuchiya, T. (1998). NorM, a putative multidrug efflux protein, of Vibrio parahaemoliticus and its homolog in Escherichia coli. Antimicrob Agents Chemother 42, 1778-1782.

Munske, G. R., Lindley, E. V. \& Magnuson, J. A. (1984). Streptococcus faecalis proton gradients and tetracycline transport. J Bacteriol 158, 49-54.

Neyfakh, A. A. (1992). The multidrug efflux transporter of Bacillus subtilis is a structural and functional homolog of the Staphylococcus NorA protein. Antimicrob Agents Chemother 36, 484-485.

Nikaido, H., Basina, M., Nguyen, V. \& Rosenberg, E. Y. (1998). Multidrug efflux pump AcrAB of Salmonella typhimurium excretes only those $\beta$-lactam antibiotics containing lipophilic side chains. J Bacteriol 180, 4686-4692.

Paulsen, I. T., Brown, M. H. \& Skurray, R. A. (1996). Protondependent multidrug efflux systems. Microbiol Rev 60, 575-608.

Perreten, V., Schwarz, F., Cresta, L., Boeglin, M., Dasen, G. \& Teuber, M. (1997). Antibiotic resistance spread in food. Nature 389, 801-802.

Putman, M., van Veen, H. W., Poolman, B. \& Konings, W. N. (1999a). Restrictive use of detergents in the functional reconstitution of the secondary multidrug transporter LmrP. Biochemistry 38, 1002-1008.

Putman, M., Koole, L. A., van Veen, H. W. \& Konings, W. N. (1999b). The secondary multidrug transporter LmrP contains multiple drug interaction sites. Biochemistry 38, 13900-13905.
Putman, M., van Veen, H. W. \& Konings, W. N. (2000). Antibiotic resistance: the era of the drug pump. Mol Microbiol 36, 772-774.

Ramaswamy, K., Harig, J. M., Kleinman, J. G., Harris, M. S. \& Barry, J. A. (1989). Sodium-proton exchange in human ileal brush-border membrane vesicles. Biochim Biophys Acta 981, 193-199.

Saier, M. H., Jr, Paulsen, I. T., Sliwinski, M. K., Pao, S. S., Skurray, R. A. \& Nikaido, H. (1998). Evolutionary origins of multidrug and drug-specific efflux pumps in bacteria. FASEB J 12, 265-274.

Travis, J. (1994). Reviving the antibiotic miracle? Science 264, 360-362.

van Veen, H. W. \& Konings, W. N. (1998). The ABC family of multidrug transporters in microorganisms. Biochim Biophys Acta 1365, 31-36.

Weisblum, B. (1995). Erythromycin resistance by ribosome modification. Antimicrob Agents Chemother 39, 577-585.

Woodward, R. B. (1957). Struktur und Biogenese der Makrolide: eine neue Klasse von Naturstoffen. Angew Chem 69, 50-58.

Yamaguchi, A., Udagawa, T. \& Sawai, T. (1990). Transport of divalent cations with tetracycline as mediated by the transposon Tn10-encoded tetracycline resistance protein. J Biol Chem 265, 4809-4813.

Yamaguchi, A., Iwasaki-Ohba, Y., Ono, N., Kaneko-Ohdera, M. \& Sawai, T. (1991). Stoichiometry of metal-tetracycline $/ \mathrm{H}^{+}$antiport mediated by the transposon $\mathrm{Tn} 10$-encoded tetracycline resistance protein. FEBS Lett 282, 415-418.

Yoshida, H., Bogaki, M., Nakamura, S., Ubukata, K. \& Konno, M. (1990). Nucleotide sequence and characterization of the Staphylococcus aureus nor A gene, which confers resistance to quinolones. J Bacteriol 172, 6942-6949.

Zwietering, M. H., Jongenburger, I., Rombouts, F. M. \& van 't Riet, K. (1990). Modelling of the bacterial growth curve. Appl Environ Microbiol 56, 1875-1881.

Received 20 February 2001; revised 1 July 2001; accepted 5 July 2001. 